\title{
Home Health Care: The Missing Link in Health Delivery System for Indian Elderly Population-A Narrative Review
}

Ankit Singh

\begin{abstract}
Elderly population in India is at a disadvantageous position in comparison to other countries in matters of dedicated health facilities, health insurance, and geriatric specialist. Health issues of the elderly can be summarized as geriatric syndromes, cognitive decline, immobility, falls, and incontinence. These peculiar health characteristics of old age population can be better dealt with home health care, which is of recent origin in India and is limited to only metro cities in the private sector. Whereas home health care in the USA is present from over a century, in Europe it is present in most of the countries. This study presents the status of existing private home health care industry of India and advocates about the benefits of home health care for the elderly and supports that Indian policymaking bodies should incorporate home health care in its policy for improving access and quality of health care to elderly population.
\end{abstract}

Keywords: Aging, Home health care, Old age dependency ratio, Silver tsunami.

How to cite this article: Singh A. Home Health Care: The Missing Link in Health Delivery System for Indian Elderly Population-A Narrative Review. Int J Res Foundation Hosp Healthc Adm 2017;5(2):89-94.

Source of support: Nil

Conflict of interest: None

\section{INTRODUCTION}

Every human has a right to health and it is the state's responsibility in India to take care of its citizen's health. Health care should be affordable, accessible, and reach all sections of society. To ensure that every country has its own customized health care system, it is divided into primary, secondary, and tertiary levels. However, it is also imperative for every country to reassess and redesign its health care system from time to time to cope with the challenges put forward by demographic and financial variables. Inadequate government provisions like social security scheme, health insurance, dedicated public health facilities for the old age population (above 60 years in India) made this section extremely vulnerable in terms of health

Assistant Professor

Department of Hospital Administration, Sikkim Manipal University, Gangtok, Sikkim, India

Corresponding Author: Ankit Singh, Assistant Professor Department of Hospital Administration, Sikkim Manipal University Gangtok, Sikkim, India, e-mail: anktsngh15@gmail.com and finance. ${ }^{1}$ On the contrary, number of decreasing joint families $^{2}$ is also worsening the situation of old age people in India. In India elderly people (60 years and above) are deprived of measures which should have been taken long back by the Government of India to maintain their quality of life. As a result, India's elderly are facing problems of economic insecurity. ${ }^{3}$ This situation becomes grave as with age health care expenditure also increases. ${ }^{4}$ In addition to that, this scenario makes the situation of Indian elderly females much worse as they are comparatively highly dependent on family members than male counterparts; for example, as per the data by National Sample Survey organization, in 2004 only 15\% of Indian rural females were economically independent, whereas for rural males this percentage was found to be $51 \%$. However, these kinds of challenges in the past are being assessed and dealt with in developed countries on a proactive basis by measures, such as social insurance schemes, dedicated health facilities, and increased health insurance, as in many developed countries health care system is predominantly government-owned. In this context, Maples ${ }^{5}$ used the phrase "Silver Tsunami" for the first time for the American aging population. He stressed upon the changing demographics and the challenges put forward by the aging population of America which was different from previous ones in terms of life expectancy, education, and lower rate of disability. Similar trends are also found in Indian aging population, which makes it imperative to learn lessons from other countries, which dealt with these problems successfully. This brings the question on how home health care can be of help for aging population? To answer this it has been well established that home health care played a vital role in Western countries in reducing the patient load in hospitals and health care professionals. For example, proper home health care is found to reduce rehospitalization, improve adherence to medication regimen, improve functional capacity, and bring cost of treatment down in patients with congestive heart failures. ${ }^{6}$ Similarly in a study done in Korea, home health care is found to improve activities of daily living (ADLs) and instrumental ADLs of home health care recipients. ${ }^{7}$

In India, home health care market is growing at a fast rate with a Compound Annual Growth Rate of $18 \%$ and is expected to reach USD 6.2 billion by $2020 .{ }^{8}$ But the year 2012 is highly significant in the Indian home health care industry when private organized home health player 


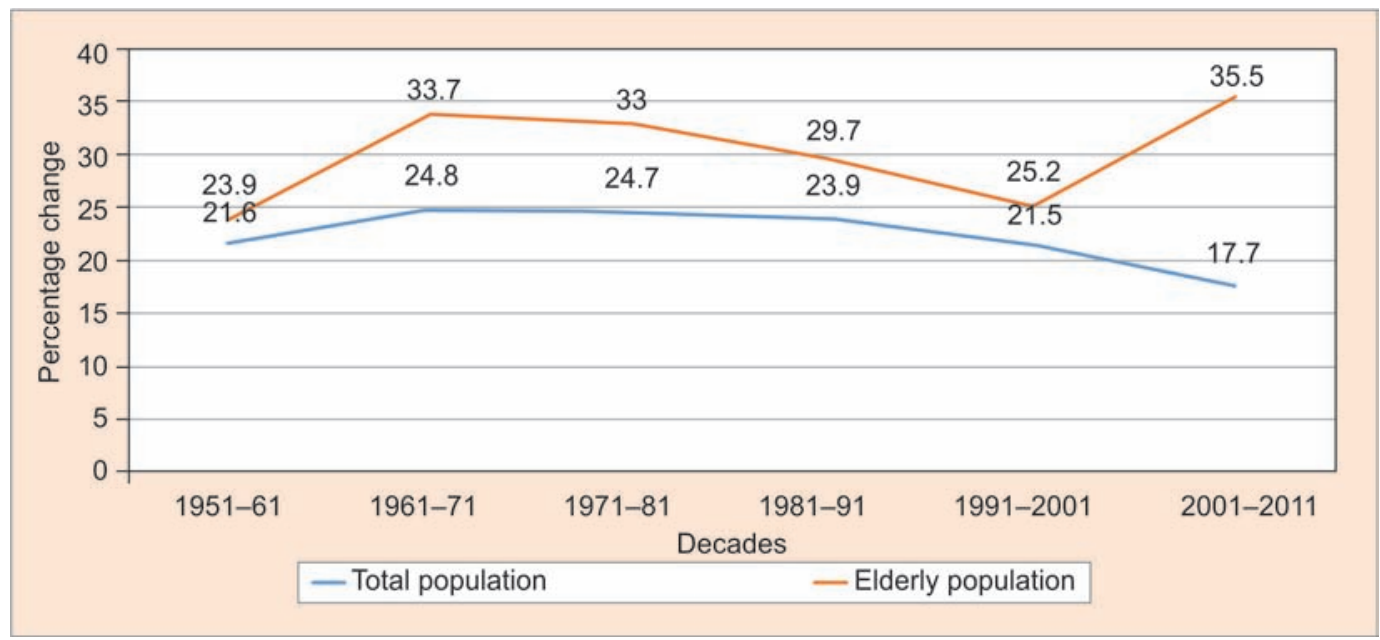

Graph 1: Decadal growth rate of general and elderly population

Source: Government of India, Ministry of Statistics and Programme Implementation, 2016

Portea Medical identified it as a viable business opportunity and started operation. It is at present the market leader of Indian home health industry. Many other private players started targeting Indian metro cities. However, in the public sector, the Ministry of Health and Family Welfare launched the National Programme for the Health Care of the Elderly (NPHCE) in the year 2011, which is still in its early years. This study is an attempt to highlight the challenges and problems faced by the elderly in India and also to suggest how home health care can fill the void of Indian health care system and minimize the health-related agony of elderly in India. This review is written after critically evaluating 47 research papers found in Google Scholar and ResearchGate with the keywords "home health care, home care, elderly abuse, elderly population trends in India, old age dependency ratio, Silver Tsunami, Ageing."

\section{POPULATION TRENDS OF ELDERLY IN INDIA}

In India, population is growing at a rate of $1.2 \%$ every year. $^{9}$ Out of the total population, $8.6 \%$ of population is above 60 years of age. Population aged 60 are higher in female subgroup ( $9 \%$ ) in comparison to male subgroup $(8.2 \%)$. It is also to be highlighted that the decadal growth rate of total population (Graph 1) is showing a declining trend, whereas the growth rate of elderly population in the decade 2001 to 2011 increased by $35.5 \% .{ }^{10}$

In India, the old age dependency ratio is $14.2 \%$. In this aspect, projection-based studies reveal that India is expected to have more than $19 \%$ of total population

* Number of dependent people per working age population.

** National Research Council. Ageing in Asia: findings from new and emerging data initiatives. Washington (DC): National Research Council; 2012. Available from: https:// www.nap.edu/catalog/13361/aging-in-asia-findingsfrom-new-and-emerging-data-initiatives. above 60 years by 2050. ${ }^{11}$ Similarly, the dependency ratio ${ }^{*}$ will rise up to $31 \%$ by 2050 .*

As per the census data of India, it was found that in the last two decades the number of elderly females outnumbered the number of elderly males, which was reverse earlier (Graph 2). It should also be noted that this poses major risk to the elderly females as they are comparatively more dependent than the elderly male counterparts. Old age dependency ratio for female in 2011 was 14.5 in comparison to male $13.6^{10}$ (Graph 3).

\section{Meaning of Silver Tsunami}

Silver means "Silver-lined hairs old people" and tsunami means something which is coming in a massive way and hard to cope with. Maples ${ }^{5}$ coined the word "Silver Tsunami" in the context of American baby-boomer generation which began to celebrate their 60th birthday by the year 2006. This generation is different from previous other generations in terms of education, family structure, life expectancy, and lower rates of disability. ${ }^{12}$

\section{HEALTH ISSUES OF ELDERLY}

At least one in every seven older adult (14\%) has at least one of the functional limitations, and functional limitation was found to be higher in older adult females in comparison to males. ${ }^{13}$ Similarly, the proportion of elderly mobile men fell from 95 to $72 \%$ in age group 60 to 64 years to above 80 years, whereas in females it fell from 95 to $63-65 \%$ from age group 60 to 64 years to above 80 years $^{14}$ (Graph 4 ).

It is also to be noted that prevalence of heart disease is more in urban elderly population than rural elderly population, whereas prevalence of ulcer is higher in rural elderly population. The prevalence of diabetes is more in urban males in comparison to rural males, whereas the same is opposite in the case of females ${ }^{10}$ (Graph 5). 


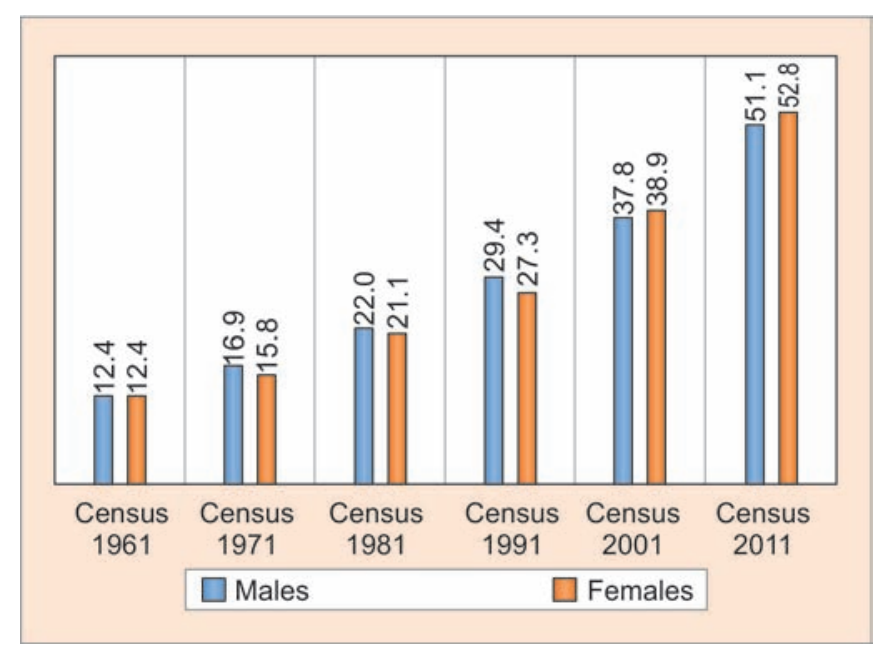

Graph 2: Gender-wise distribution of elderly population of India (data in millions)

Source: Government of India, Ministry of Statistics and Programme Implementation, 2016

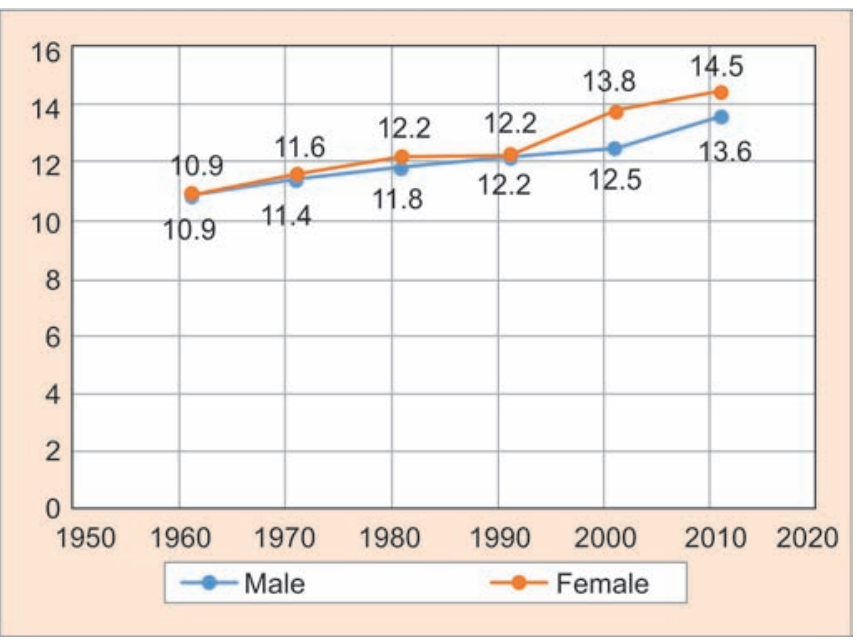

Graph 3: Old age dependency ratio by gender in India, 1961 to 2011 Source: Government of India, Ministry of Statistics and Programme Implementation, 2016

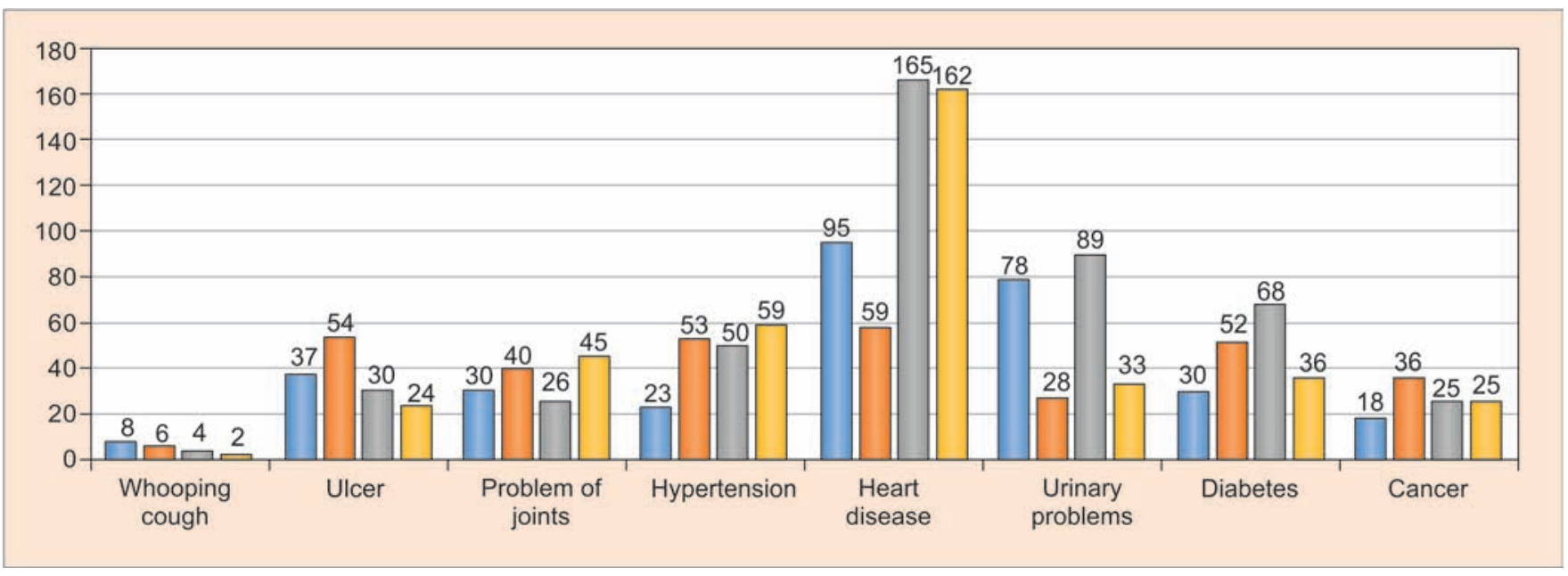

Graph 4: Number of elderly person reporting chronic disease (per 1,000 persons) Source: National Sample Survey, 2004

Talking about the chronic disease profile of elderly in India, the big four are heart disease (31\%), urinary problems (15\%), hypertension, and diabetes (12\% each).

The implication of Silver Tsunami on health care will be increased utilization of health care services and resources by old age people, increased overall cost of health care, and shortage of health care professionals. Old age is also characterized by mental illnesses, such as dementia, and in dementia Alzheimer's disease is highly prevalent in old age people. For example, in Canada two-thirds of elderly with dementia above 65 years are suffering from Alzheimer's disease. ${ }^{15}$ Similarly, in a study done in the USA, it was found that despite the efforts by the government to promote geriatric care, enrolment in geriatrics training program across different profession is not increasing and health professional graduates are lacking formal training in care of older adults. ${ }^{16}$

The condition is worse in India as the geriatric care in India is in its nascent stage. There are very few geriatric care professionals in India and in a country of 1.3 billion people only one seat is for DM Geriatric mental health and 22 medical seats are for MD Geriatrics annually. ${ }^{\dagger}$ The patients of elderly age group are treated majorly by internal medicine experts in India but the health needs of an elderly are peculiar and require specialized attention, which should be provided only by a specialist in geriatrics.

\section{HOME HEALTH CARE AND AGING}

In India, there is shortage of health care professionals as the total numbers of allopathic doctors, nurses, and midwifes are 11.9 per 10,000 population, which is half of World Health Organization benchmark of 25.4 workers per 10,000 population. ${ }^{17}$ In addition to that, in the Indian health care workforce of allopathic doctors, there is underrepresentation of women as females are only $17 \%$ of

\footnotetext{
${ }^{\dagger}$ http://www.mciindia.org/.
} 


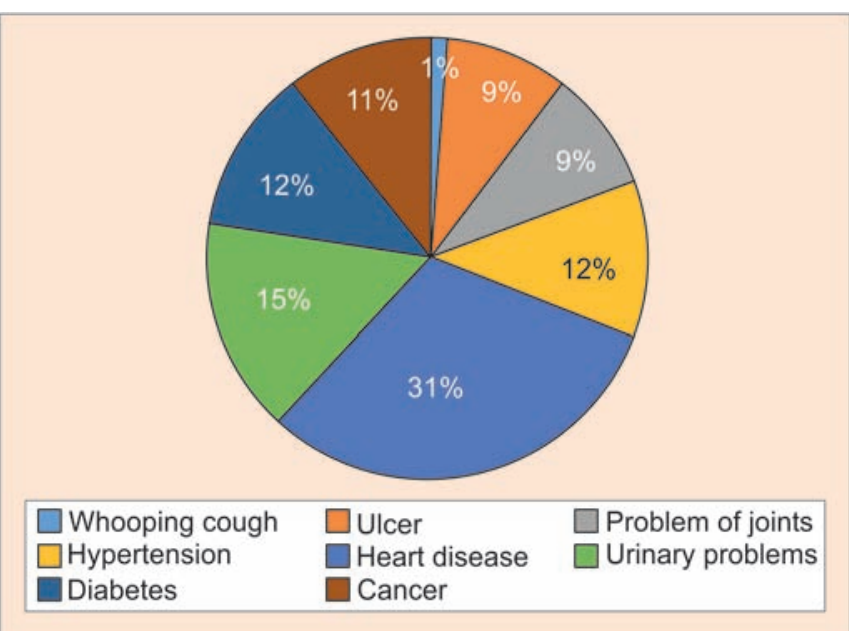

Graph 5: Chronic disease profile of elderly in India Source: National Sample Survey, 2004

all allopathic doctors. However, this underrepresentation of women in health care can affect the access to health care of elderly females as well. Authors have advocated for an integrated home care-based approach for geriatric patients. In their study they found this approach resulted in reduced hospitalization and decreased cost of treatment. ${ }^{18}$ Home health care can also be a solution for the shortage of manpower as it focuses on preventive aspect of care and it provides a new set of health care professionals who can assist physicians in care delivery at home. ${ }^{19}$ Moreover, surveys of older adults indicate that they have a strong desire to remain in the community as long as possible. ${ }^{\ddagger}$

Studies have shown that elders living alone are at high risk of health. ${ }^{20,21}$ Complementary to this, various studies have supported the fact that multigenerational household contributes to health gains as it provides benefits, such as family support, active grand parenting roles, healthier lifestyle, e.g., giving up smoking for grandchildren's, and assistance in day-to-day activities. $^{22}$

\section{ELDERLY AS MAJOR USERS OF HOME HEALTH CARE}

In a study done in Sweden, it was found that women are comparatively more heavy users of home health services and the consumption of home health services increases with age. ${ }^{23}$ Both these trends are present in Indian demography as the life expectancy in India for women increased more in comparison to men for the period 1990

\footnotetext{
${ }^{\ddagger}$ National Council on Aging. The United States of Aging Survey. Arlington (VA): National Council on Aging; 2015 [cited 2015 Dec 7]. Available from: https://www.ncoa.org/ news/usoa-survey/.
}

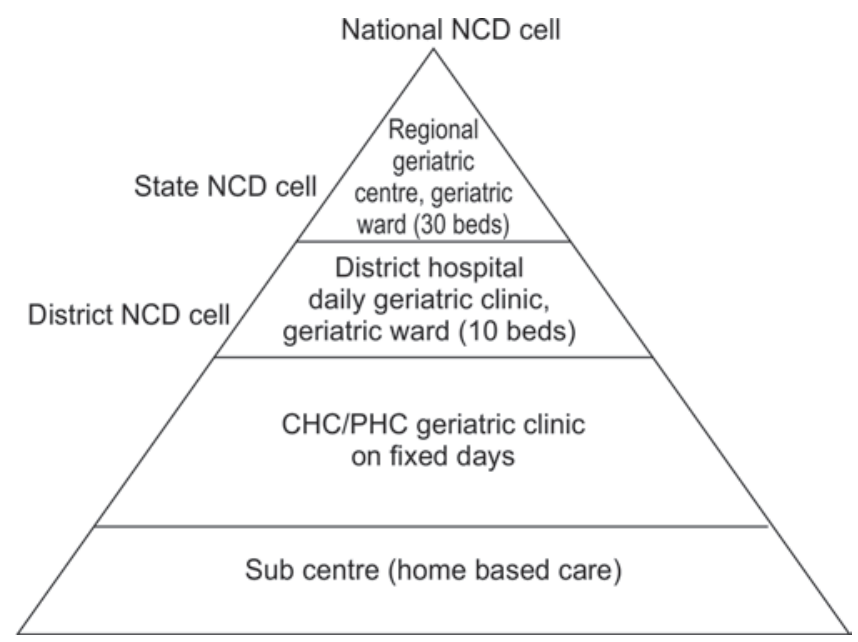

Graph 6: National program for health care of elderly levels of care Source: Operational guidelines: National programme for healthcare of the elderly (NPHCE), p. 5

to $2003^{\text {II }}$ and reasons for this shift cited are low level of mortality, fertility, and high life expectancy. ${ }^{24}$

India's aging population is a significant contributor for making India a lucrative market for home health care service providers. Majority of home health service providers in India have elderly care in their service offering list, however, the service type, service pricing, service packaging vary from organization to organization, and the organization are still trying to come up with the best fit for the Indian market.

\section{HOME HEALTH CARE IN INDIA}

India came up with the National policy for older persons in 1999, with the aim of assisting older people to live an independent life. In 2007, it became a matter of sate obligation under "Maintenance and Welfare of Parents and Senior Citizens Act, 2007." To address the health needs of older citizens of India, in 2011, the Ministry of Health and Family Welfare launched NPHCE. The interventions designed were in preventive, curative, and rehabilitative domains of the geriatric field ${ }^{\S}$ (Graph 6).

In NPHCE, it is acknowledged that India lacks the model, such as home-based care and insurance for elderly people to cater to the needs of elderly people; for example, in India the insurance schemes for poor cover only those aged 65 years or younger." In NPHCE, as per the operational guidelines, domiciliary visits for

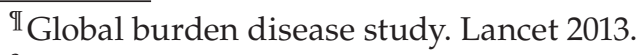

$\S$ National programme for health care of the elderly, Ministry of Health and Family Welfare, Government of India, 2011.

\# Ageing in Asia: findings from new and emerging data initiatives. 2012.
} 
home-bound patients at the subcenter level are incorporated, which supports the view that home health care is now considered as a measure to improve the condition of elderly people even by government agencies in India.

On the contrary, at the time of independence, only $8 \%$ of Indian health care delivery was private and now Indian health care system is dominated by private players and around $87 \%$ of India's health care is privately funded. ${ }^{25}$ This phenomenon is also seen in home health care segment of Indian health care system as it is now considered as an attractive venture for investors, and more and more players are entering with the passage of time.

\section{KEY PRIVATE PLAYERS OF INDIAN HOME HEALTH CARE INDUSTRY}

Nightingales, the home health specialist, claims itself of having 18 years of experience in home health care, although in the early years the home health service provided by them was unorganized and was limited to supply of qualified nurses, but in 2014 at the time of acquisition by Medwell Ventures, it was providing 53,000 bedside nursing days per annum, 24,000 medical services per year, and 5,000 families were subscribed under its annual care plan. In the initial phase, majority of organizations were tapping metros and tier 1 cities based on the data collected from individual organizational websites. More number of home health care organizations are in southern part of India, basically clustered around Bengaluru, Chennai, and Hyderabad, such as India Home Health care, Portea Medical, Nightingales, Apnacare, Health Heal, etc. In India, home health care started its operations in 2009, whereas the current market leader based on presence is Portea Medical, with 25 branches all over India. It started its operations in the year 2013. The year 2013 was very significant in the home health care industry in India as in this year US-based Bayada Home

Table 1: Recent investments in home health care segment

\begin{tabular}{|c|c|c|c|}
\hline $\begin{array}{l}\text { Name of } \\
\text { organization } \\
\text { and year }\end{array}$ & Location & Investor & $\begin{array}{l}\text { Amount } \\
\text { (in million \$) }\end{array}$ \\
\hline $\begin{array}{l}\text { Pramati Care } \\
\text { (2016) }\end{array}$ & Noida & $\begin{array}{l}\text { Marquee Angel } \\
\text { Investors }\end{array}$ & 0.20 \\
\hline Care24 (2016) & Mumbai & $\begin{array}{l}\text { India Quotient, SAIF } \\
\text { Partners }\end{array}$ & 4.35 \\
\hline Portea (2015) & Bengaluru & $\begin{array}{l}\text { Accel Partners, } \\
\text { VentureEast, } \\
\text { Qualcomm } \\
\text { Ventures }\end{array}$ & 37.5 \\
\hline $\begin{array}{l}\text { Life Care } \\
\text { Health (2016) }\end{array}$ & Hyderabad & sos & 0.15 \\
\hline $\begin{array}{l}\text { MyCareLine } \\
(2016)\end{array}$ & Delhi & Angel Investment & 0.5 \\
\hline
\end{tabular}

Health care bought $26 \%$ stake in Chennai-based India Home Health Care ${ }^{\$}$ and after that various other organizations got funding. To name a few, Portea Medical raised 8 million dollars from Accel Partners and VentureEast (Table 1), Medwel Ventures purchased Nightingales for undisclosed amount in 2014, Homital Medcare started operations with seed funding from RR energy.

Similarly in the year 2016, strategic acquisitions were done by the key players like Portea Medical which acquired Health Mantra to strengthen their records management system and PSTakeCare to gain the access for proven platform for connecting stakeholders like Super specialists and specialists with the patients (Table 2).

Now home health care is spreading to other parts of the country also, like Mumbai with the increased presence of home health service providers, such as Zoctr, Arooj Home Health care, Portea, India Home Health care, Nightingales, and Care 24, whereas in Kolkata Tribeca Care and Portea are the major players. In NCR-Delhi, Health care at Home, Pramati Care are increasing their footprints.

\section{CONCLUSION}

The growth in numbers of private home health service providers and the increased preference of home health services by Indian elderly population in last decade clearly indicate the missing market of home health services for Indian elderly population, which is still absent in the public sector. Access to these services will be a critical issue as high cost serves as a significant hindrance and pushes home health care market toward market failure.

Table 2: Recent acquisitions in home health care industry

\begin{tabular}{|c|c|c|c|}
\hline $\begin{array}{l}\text { Month } \\
\text { and year }\end{array}$ & Target firm & Acquirer & Rationale \\
\hline Jul-16 & Health Impetus & $\begin{array}{l}\text { Health care } \\
\text { at Home } \\
\text { India }\end{array}$ & $\begin{array}{l}\text { Disease management } \\
\text { firm }\end{array}$ \\
\hline Mar-16 & Health Mantra & $\begin{array}{l}\text { Portea } \\
\text { Medical }\end{array}$ & $\begin{array}{l}\text { To strengthen } \\
\text { financing services and } \\
\text { records management } \\
\text { services }\end{array}$ \\
\hline Jan-16 & PSTakeCare & $\begin{array}{l}\text { Portea } \\
\text { Medical }\end{array}$ & $\begin{array}{l}\text { To get access to } \\
\text { a proven platform } \\
\text { for connecting } \\
\text { stakeholders of health } \\
\text { care ecosystem }\end{array}$ \\
\hline Nov-15 & MedibyzPharma & $\begin{array}{l}\text { Portea } \\
\text { Medical }\end{array}$ & $\begin{array}{l}\text { To provide pharmacy } \\
\text { services to chronic } \\
\text { disease patients }\end{array}$ \\
\hline
\end{tabular}

${ }^{\$}$ Reuters. Feb 2014. http://blogs.reuters.com/india/ 2014/02/05/health-start-ups-tap-indias-growing-homecare-sector $/$. 
Indian policymaking bodies should identify this gap and should come up with a policy on home health care which stresses on development of infrastructure for home health services. Indian policymaking bodies should also devise an insurance scheme that will increase the access of Indian elderly for the home health services.

\section{REFERENCES}

1. Irudaya Rajan I. Population ageing and health in India. Centre for enquiry into health and allied themes survey no. 2804 \& 2805. Mumbai: Centre for Enquiry into Health and Allied Themes; 2006.

2. Singh JP. Problems of India's changing family and state intervention. Eastern Anthropol 2010 Jan-Mar;63(1):17-40.

3. Bloom DE, Mahal A, Rosenberg L, Sevilla J. Economic security arrangements in the context of population ageing in India. Int Soc Sec Rev 2010 Jul;63(3-4):59-89.

4. de Meijer C, Wouterse B, Polder J, Koopmanschap M. The effect of population aging on health expenditure growth: a critical review. Eur J Ageing 2013 May;10(4):353-361.

5. Maples MF. Spirituality, wellness and the "Silver Tsunami": implications for counseling. Alexandria (VA): American Counseling Association; 2007 [cited 2007 Aug 28]. Available from: http://counselingoutfitters.com/vistas/vistas07/ Maples.htm.

6. Maliakkal AV, Sun AZ. Home care program reduces hospital readmissions in patients with congestive heart failure and improves other associated indicators of health. Home Health Care Manage Pract 2014 Apr;26(4):191-197.

7. Han SJ, Kim HK, Storfjell J, Kim MJ. Clinical outcomes and quality of life of home health care patients. Asian Nurs Res (Korean Soc Nurs Sci) 2013 Jun;7(2):53-60.

8. Singh B.CMR's India Home Healthcare Report 2016. Bengaluru: CMR; 2016 [cited 2016 Jul 22]. Available from: http://cmrindia.com/cmrs-india-home-healthcare-report-2016/.

9. Population growth (annual \%). (n.d.). Retrieved September 03, 2017, from https://data.worldbank.org/indicator/SP.POP. GROW?locations=IN.

10. Government of India, Ministry of Statistics and Programme Implementation, Central Statistics office. Elderly in India. New Delhi: Government of India; 2016.

11. United Nations. World Population Prospects: The 2015 Revision. United Nations Department of Economic and Social Affairs Population Division. Geneva; United Nations; 2015.
12. Booth L, Brockway K. Legal and ethical issues in gerontological counselling. Paper presented in CEP780 Class: legal and ethical issues in counselling, University of Nevada, Reno. 2006.

13. Kastor A, Mohanty SK. Associated covariates of functional limitation among older adults in India: an exploration. Ageing Int 2016 Jun;41(2):178-192.

14. Population census of India. 2011.

15. Lindsay J, Laurin D, Verreault R, Hébert R, Helliwell B, Hill GB, McDowell I. Risk factors for Alzheimer's disease: a prospective analysis from the Canadian Study of Health and Aging. Am J Epidemiol 2002 Sep;156(5):445-453.

16. Heflin MT. Surviving the Silver Tsunami: training a health care workforce to care for North Carolina's Aging Population. N C Med J 2016 Mar-Apr;77(2):102-106.

17. Rao KD, Bhatnagar A, Berman P. So many, yet few: Human resources for health in India. Hum Resour Health 2012 Aug;10(1):19.

18. Landi F, Onder G, Russo A, Tabaccanti S, Rollo R, Federici $\mathrm{S}$, Bernabei R. A new model of integrated home care for the elderly. J Clin Epidemiol 2001 Sep;54(9):968-970.

19. Suter P, Hennessey B, Harrison G, Fagan M, Norman B, Suter WN. Home-based chronic care. An expanded integrative model for Home Health Professionals Home health is poised to become the leader of chronic care disease management. Home Healthc Nurse 2008 Apr;26(4):222-229.

20. Cui ZJ. Living arrangements and the health status of the elderly in rural China. Mumbai: International Institute for Population Sciences; 2002.

21. Chen F, Short S. Household context and subjective wellbeing among the oldest old in China. J Fam Issues 2008 Oct;29(10):1379-1403.

22. Ofstedal MB, Reidy E, Knodel J. Gender differences in economic support and well-being of older Asians. J Cross Cult Gerontol 2004 Sep;19(3):165-201.

23. Zielinski A, Halling A. Association between age, gender and multimorbidity level and receiving home health care: a population-based Swedish study. BMC Res Notes 2015 Nov; $8: 714$.

24. Johnson CS, Stevens A, Rajan I. Promotion of healthy aging in the context of population aging phenomenon: a look at the aging state in India. Indian J Gerontol 2005;19(2-4): 181-192.

25. Loh LC, Ugarte-Gil C, Darko K. Private sector contributions and their effect on physician emigration in the developing world. Bull WHO 2013 Jan;91(3):227-233. 